\title{
Transcatheter treatment of pulmonary stenosis and coarctation of the aorta: experience with percutaneous balloon dilatation
}

\author{
P SYAMASUNDAR RAO \\ From the Department of Paediatrics, King Faisal Specialist Hospital and Research Centre, Riyadh, \\ Saudi Arabia
}

SUMMARY Twenty two children (age range 4 months-20 years) with pulmonary valve stenosis and ten children (age range 1 month-11 years) with coarctation of the aorta underwent balloon dilatation in the 29 month period between October 1983 and February 1986. Number 5-9 French catheters with $5-20 \mathrm{~mm}$ balloons were used according to the size of the angiographically measured pulmonary valve annulus or coarcted segment and the aorta proximal to coarctation. The peak inflation pressure used in the balloons varied from $2-5 \mathrm{~atm}\left(202-505 \mathrm{kN} / \mathrm{m}^{2}\right)$ for pulmonary valve stenosis and $4-8 \mathrm{~atm}\left(404-808 \mathrm{kN} / \mathrm{m}^{2}\right)$ for coarctation, and inflation lasted 8-15 s. At least four balloon dilatations were performed in every case. After balloon dilatation the mean (SD) peak systolic pressure gradient across the pulmonary valve fell from 98 (39) to 33 (13) $\mathrm{mm} \mathrm{Hg}$. The cardiac index did not change.

After balloon dilatation of aortic coarctation the systolic pressure in the descending aorta rose from $86.4(17.7)$ to $107.8(20) \mathrm{mm} \mathrm{Hg}$ and the peak systolic pressure difference across the coarctation fell from $44.1(19.1)$ to $8.5(8.5) \mathrm{mm} \mathrm{Hg}$. The diameter of the angiographically measured coarcted segment increased, the Doppler estimate of the pressure difference across the coarctation decreased, and the femoral pulses improved. There were no important complications. Long term follow up results for balloon dilatation of pulmonary valve stenosis were excellent. Similar follow up was not available for patients after dilatation of aortic coarctation.

Percutaneous balloon dilatation for pulmonary stenosis and coarctation of the aorta is a safe and effective alternative to operation. It is the treatment of choice for pulmonary valve stenosis and it may become so for coarctation of the aorta in young children if long term results are favourable.

Although the technique of balloon dilatation of stenotic lesions was described by Rubio and LimonLason in $1954^{1}$ and Dotter and Judkins in $1964,{ }^{2}$ it became popular only after Grüntzig and associates applied similar techniques for dilatation to cases of coronary artery stenosis in the mid-1970s. ${ }^{34}$ More recently, similar techniques have also been used in infants and children to relieve congenital and postoperative stenotic lesions of the pulmonary valve, ${ }^{5-7}$ peripheral or main pulmonary artery, ${ }^{89}$

Requests for reprints to Dr P Syamasundar Rao, Department of Pediatrics, King Faisal Specialist Hospital and Research Centre, PO Box 3354, Riyadh 11211, Kingdom of Saudi Arabia.

Accepted for publication 14 April 1986 pulmonary vein, ${ }^{10-12}$ aortic valve, ${ }^{13}$ native ${ }^{14-16}$ and re-stenosed surgically resected ${ }^{17-19}$ coarctation of the aorta, interatrial baffle obstruction after Mustard's operation for transposition of the great arteries, ${ }^{82021}$ and superior venal caval obstruction. ${ }^{22}$ This paper presents the experience with percutaneous balloon dilatation of pulmonary valve stenosis and coarctation of the aorta over the past 29 months at the King Faisal Specialist Hospital and Research Centre.

\section{Patients and methods}

PULMONARY VALVE STENOSIS

During the 29 month period from October 1983 to February 1986, twenty two children (13 boys and 9 
Table 1 Results of percutaneous balloon dilatation of pulmonary valve stenosis

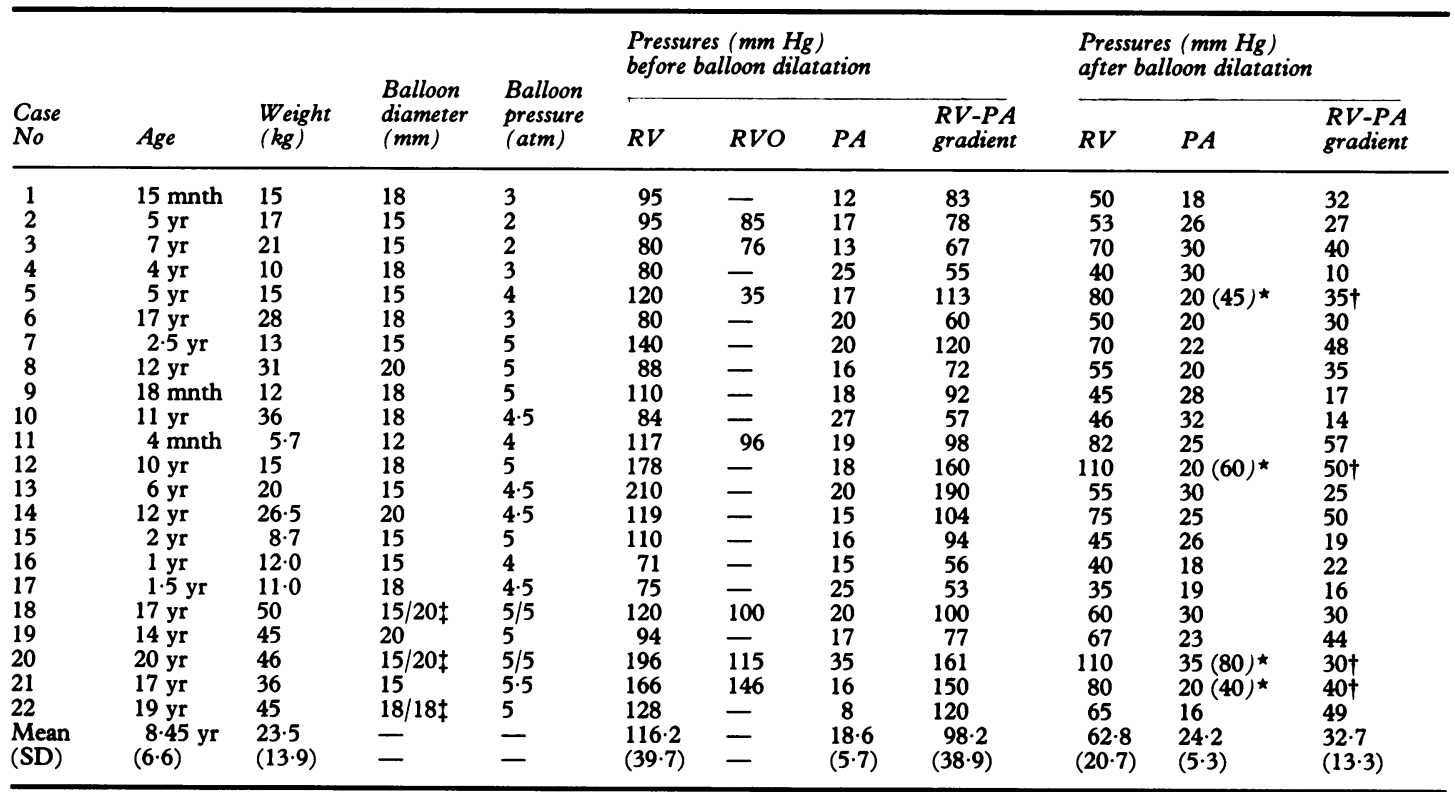

*Values in parentheses are systolic pressures in RVO after balloon dilatation of the pulmonary valve.

†The RV-PA gradient is across RVO and is likely to regress (see text).

IIn these three patients two balloons were simultaneously inflated for pulmonary valvuloplasty.

$\mathrm{RV}$, right ventricle; PA, pulmonary artery; RVO, RV outflow. $1 \mathrm{~atm}=101 \mathrm{kN} / \mathrm{m}^{2}$.

girls) aged 4 months to 20 years (median age 6 years) who weighed $5 \cdot 7-50 \mathrm{~kg}$ underwent percutaneous balloon pulmonary valvuloplasty for relief of stenosis of the pulmonary valve. Informed consent was obtained from the parents of each patient. The data obtained and the technique of balloon dilatation are described in detail elsewhere. ${ }^{5-7}$ Table 1 lists the diameter of the balloons used and the pressures applied. Two balloons were used simultaneously in three patients because the pulmonary valve annulus was too large for a single balloon. Clinical and echocardiographic/Doppler data were obtained at follow up in 12 patients and data from repeat cardiac catheterisation were available in ten.

\section{COARCTATION OF THE AORTA}

During the eight month period from February 1985 to September 1985, 10 children (eight boys and two girls) aged one month to 11 years (median age 18 months) who weighed $3.6-28 \mathrm{~kg}$ underwent balloon dilatation for aortic coarctation. Informed consent was obtained from the parents of each patient.

After clinical assessment and chest $x$ ray, electrocardiogram, $\mathbf{M}$ mode, cross sectional, and Doppler echocardiographic studies cardiac catheterisation was performed. Percutaneous right femoral venous catheterisation was performed. Oxygen saturations and pressure recordings were recorded. Percutaneous femoral artery catheterisation was also performed. A 3-7 French pigtail or multipurpose catheter was used according to the size of the patient. In each case 100 units $/ \mathbf{k g}$ (maximum of 2000 units) of heparin was administered immediately after the introduction of the arterial catheter. After the pressures across the coarctation had been measured cineangiography was performed and a final diagnosis was made in each case. An appropriate $(0.025$ to 0.038 inch) flexible tip guide wire was passed into the ascending aorta via the catheter that was already in place.

The angiographic catheter was replaced (over the guide wire) with a 5 to 9 French Grüntzig or Meditech balloon dilatation catheter (table 2). The balloon size was two times (or more) the lumen diameter of the coarcted aortic segment as measured from the cineangiogram performed before balloon dilatation (table 2), but no larger than the narrowest segment of the aorta proximal to the coarctation; the inflated balloon size varied from 5 to $15 \mathrm{~mm}$ (table 2). The balloon was 3-4 cm long. The balloon was inflated with diluted contrast material to approximately 4 to $8 \mathrm{~atm}\left(404-808 \mathrm{kN} / \mathrm{m}^{2}\right)$. Air 
Table 2 Results of percutaneous balloon dilatation (PBD) of coarctation of the aorta

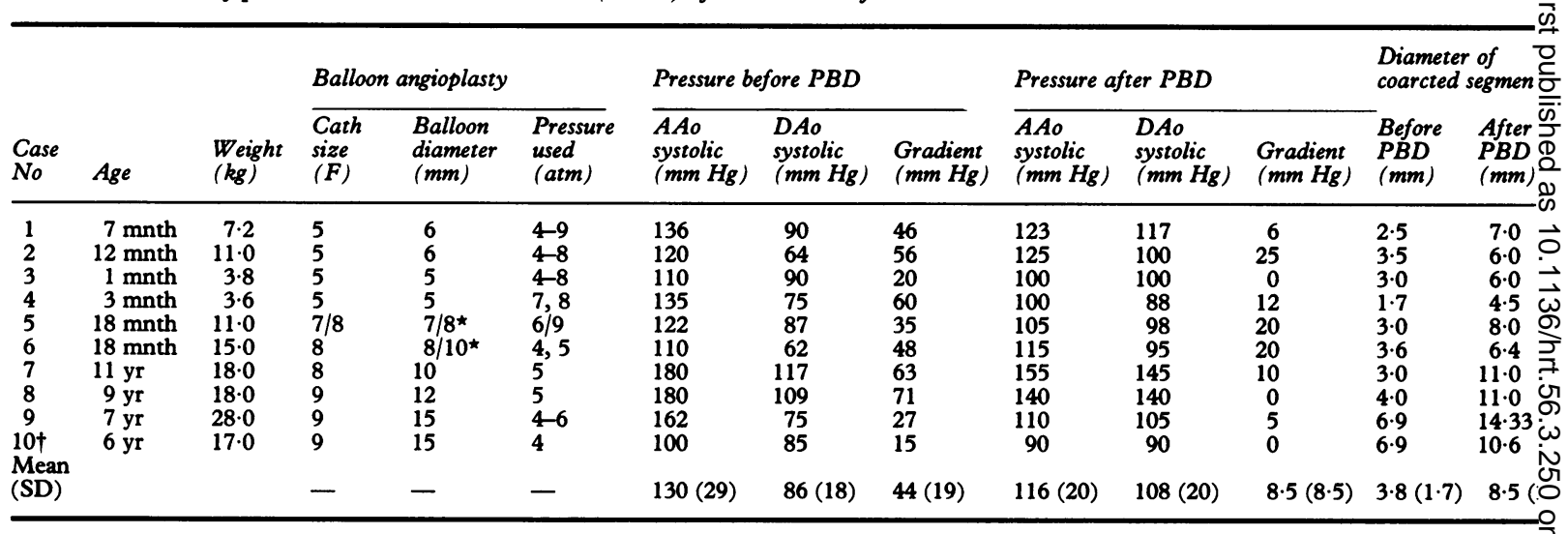

*Balloon dilatation was performed with larger sized balloons because it was felt that there was not an adequate dilatation with the initial chosen ballc †This patient also had severe aortic valve stenosis which was also dilated successfully shortly before the dilatation of aortic coarctation.

AAo, ascending aorta; DAo, descending aorta. $1 \mathrm{~atm}=101 \mathrm{kN} / \mathrm{m}^{2}$.

bubbles were eliminated from the balloon. In two patients balloon inflation pressure was increased to $9 \mathrm{~atm}\left(909 \mathrm{kN} / \mathrm{m}^{2}\right)$ and both these balloons ruptured, but no adverse effects were observed and no part of the balloon material was missed. Inflation lasted 8-15 s for each dilatation. The position of the balloon was confirmed by fluoroscopy, which showed its hour glass shape during the initial phases of inflation. Dilatation was performed on four or more occasions at intervals of at least $5 \mathrm{~min}$. During balloon inflation the following were recorded: an electrocardiogram (all cases) and, when feasible, pressure in the left ventricle (two cases), ascending aorta (two cases), or descending aorta (one case). The balloon dilatation catheter was replaced (over the guide wire) by an angiographic catheter. At no time was a catheter or guide wire manipulated over the area of the aorta in which coarctation had been dilated. Aortic or left ventricular cineangiograms were obtained after the procedure.

Fifteen minutes after the final balloon dilatation a pullback pressure tracing was recorded across the coarctation. The femoral pulses and blood pressure were measured on the morning after balloon dilatation. A cross sectional echocardiogram and the Doppler peak flow velocity in the descending aorta were recorded 18-24 hours after balloon dilatation in the last six cases. In six patients both clinical and Doppler echographic follow up were available.

Student's $t$ test was used to compare data obtained before and after balloon dilatation.

\section{Results}

PULMONARY VALVE STENOSIS

Right ventricular pressure ranged from 71 to
$210 \mathrm{~mm} \mathrm{Hg}$. In most patients there was a pressure drop across the pulmonary valve; in seven patients there was also a significant gradient across the right ventricular infundibulum (table 1 ). In every case right ventricular angiography showed evidence of a stenotic pulmonary valve. Infundibular obstruction was noted in the seven patients in whom an infundibular pressure gradient was recorded and in two patients (cases 12 and 13) in whom the pressure gradient was not recorded.

After balloon dilatation the mean (SD) right ventricular peak systolic pressure decreased from 116 (40) to $63(21)(p<0.001)$ and the systolic pressure gradient across the pulmonary valve decreased from 98 (39) to 33 (13) $\mathrm{mm} \mathrm{Hg}$ ( $\mathrm{p}<0.001$ ) (fig 1). The mean pulmonary artery pressure increased from 19 (6) to $24(5)(p<0.01)$. The cardiac index did not change significantly $(\mathrm{p}>0.1)$ after balloon dilatation $\left(3.65(0.73)\right.$ vs $\left.3.53(0.73) 1 / \mathrm{min} / \mathrm{m}^{2}\right)$. The "waist" on the balloon suddenly disappeared and the width of the jet of the contrast material increased as the balloon passed through the pulmonary valve.

Premature ventricular contractions and sinus tachycardia occasionally occurred during balloon inflation. During balloon inflation the femoral artery pressure fell and the right ventricular systolic pressure increased. Deflation of the balloon caused prompt return of the femoral artery pressure towards normal, a fall in the right ventricular pressure, and sinus or junctional bradycardia that returned to control values within about $20 \mathrm{~s}$. The balloon did not rupture in any of our cases. In two children there was serious blood loss during exchange of the catheters and guide wires, but prompt replacement prevented any deleterious consequences. There were no other complications. 


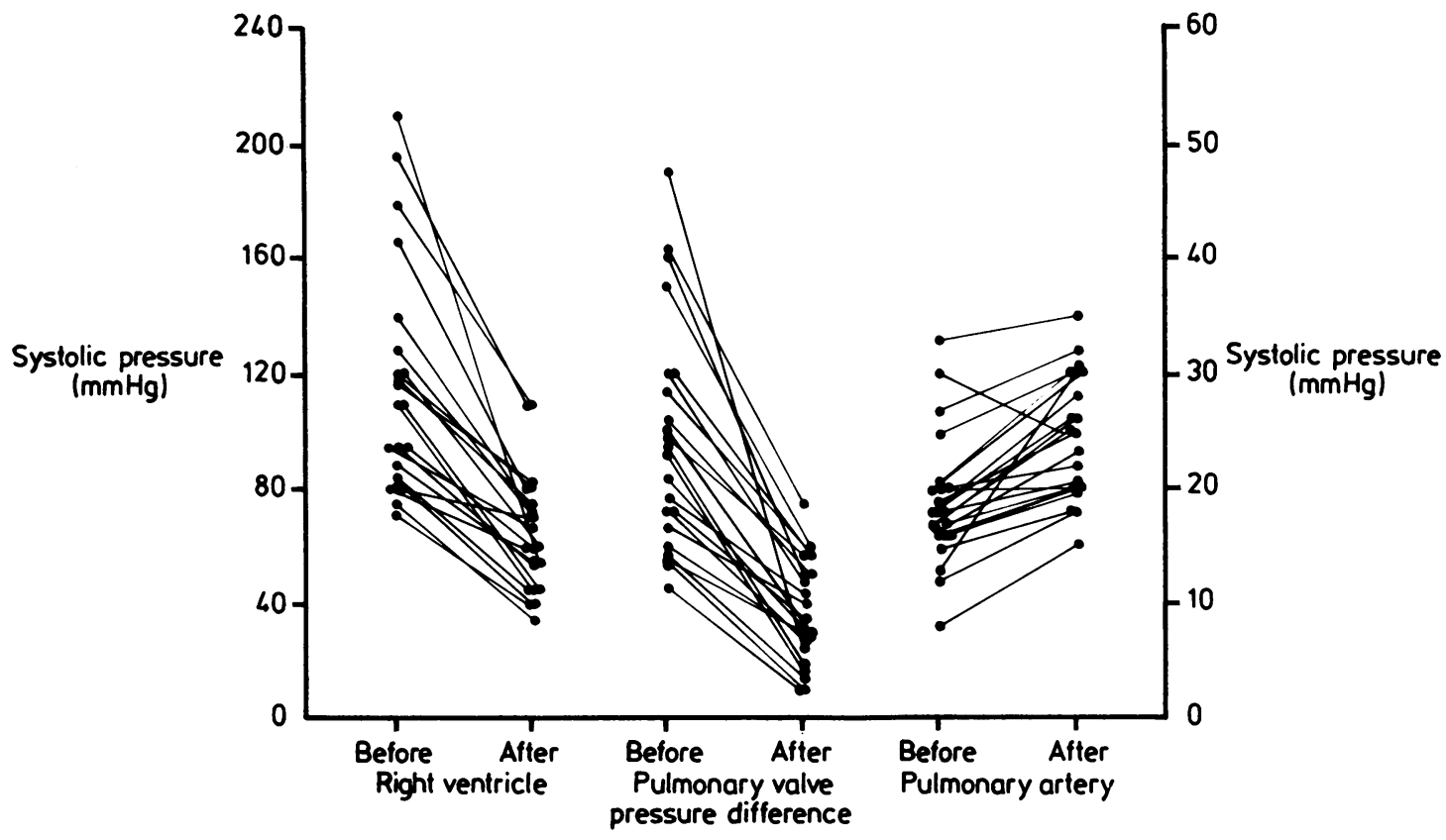

Fig 1 Peak systolic pressures in the right ventricle and pulmonary artery and pressure difference across the pulmonary valve before and after balloon dilatation of pulmonary valve stenosis. There was a significant decrease in right ventricular peak systolic pressure and pulmonary valve pressure difference after valvuloplasty. Pulmonary artery pressure increased slightly.

Post-dilatation gradients were estimated from the peak flow velocity Doppler recording in the main pulmonary artery ${ }^{23}$ in twelve patients and in all but one of them the estimated gradient had decreased.

Follow up clinical and echocardiographic and Doppler data were available in twelve of the 22 patients (follow up lasted 3-28 months; mean and median 11 months). In all patients short grade 2/6-3/6 ejection systolic murmurs that were most intense in early systole were heard at the sternal border. These were consistent with residual mild pulmonary valve stenosis. Diastolic murmurs indicative of pulmonary valve insufficiency were heard in two patients. The right ventricular end diastolic dimension decreased from $21.4(3.6)$ to $17.6(3.9) \mathrm{mm}$ (p < $0.05)$. A fall in peak Doppler flow velocity in the main pulmonary artery from $4.1(0.8)$ to 2.4 $(0.4) \mathrm{m} / \mathrm{s}(\mathrm{p}<0.001)$ indicated a significant fall in the pressure difference across the pulmonary valve. There was Doppler evidence of mild pulmonary insufficiency (sample volume placed in right ventricular outflow tract) in six of these twelve children, although only two of them had evidence of pulmonary insufficiency at auscultation. Repeat cardiac catheterisation was performed in ten patients 6-15 months (mean 10 months) after balloon dilatation.
The mean peak systolic pressure gradient across the pulmonary valve which was $96 \mathrm{~mm} \mathrm{Hg}$ (range $55-150 \mathrm{~mm} \mathrm{Hg}$ ) before dilatation fell immediately after dilatation to $37 \mathrm{~mm} \mathrm{Hg}$ (range $10-60 \mathrm{~mm} \mathrm{Hg}$ ) and later to $21 \mathrm{~mm} \mathrm{Hg}$ (range $5-35 \mathrm{~mm} \mathrm{Hg}$ ). Similarly, mean right ventricular peak systolic pressure, having been reduced from $114 \mathrm{mmHg}$ (range $80-166)$ to $60 \mathrm{~mm} \mathrm{Hg}(40-80 \mathrm{~mm} \mathrm{Hg})$ by balloon dilatation, decreased further to $44 \mathrm{~mm} \mathrm{Hg}$ (range 25 to 60). Post-dilatation cardiac catheterisation is planned for the remaining patients approximately one year after the procedure.

\section{COARCTATION OF THE AORTA}

Six of the 10 children were $<18$ months old (table 2 ). Seven had other cardiac defects including aortic stenosis (severe in two and mild in three), small ductus arteriosus (in three), and moderate sized ventricular septal defect (in one). One of these children had Turner's syndrome. None of these children had been operated upon previously for coarctation of the aorta. Four of the six infants were in moderate heart failure and all were hypertensive. Two of the four children were markedly hypertensive but none was in heart failure. Table 2 lists the technical details of balloon dilatation. One of these children (case 10) 


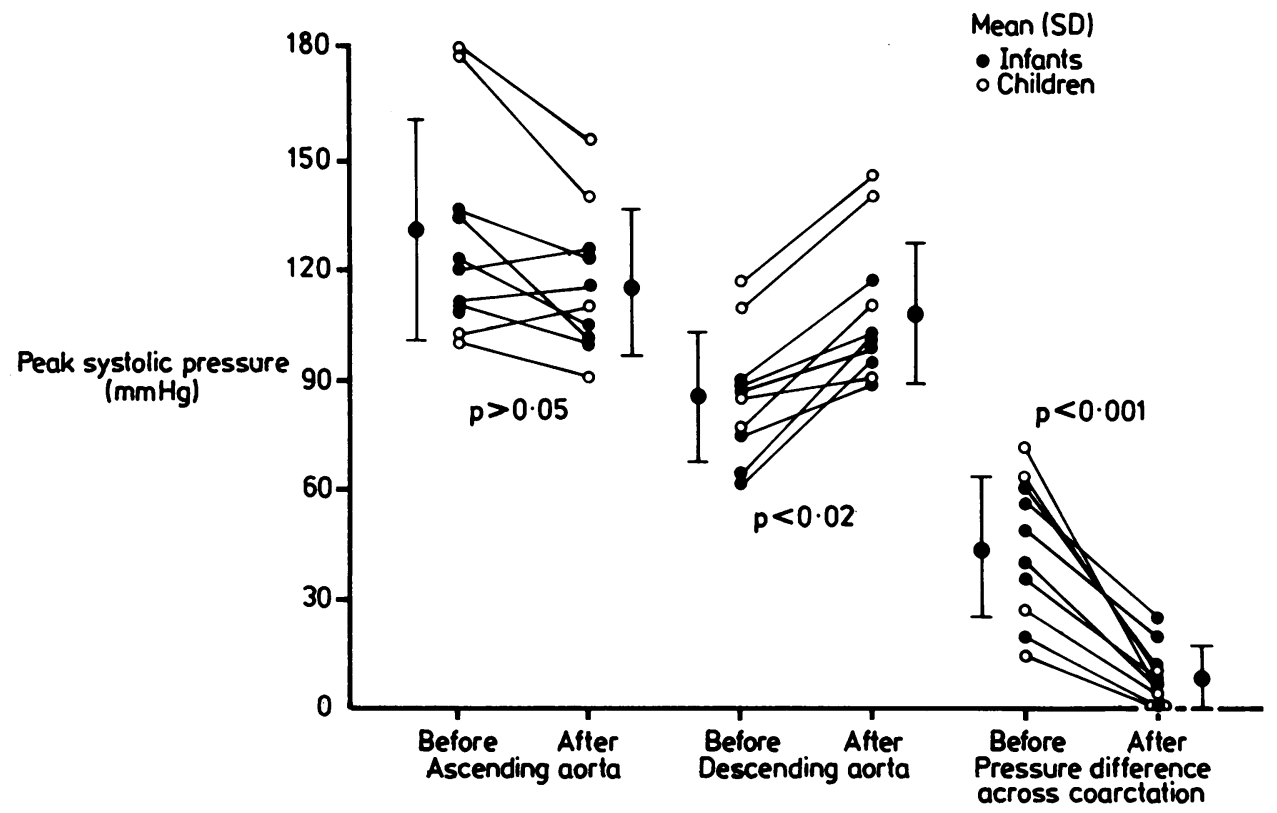

Fig 2 Peak systolic pressure in the ascending and descending aorta and systolic pressure difference across the coarctation of the aorta before and after percutaneous balloon angioplasty. There was a significant decrease $(p<0.02)$ in the descending aortic pressure while the ascending aortic pressure did not significantly decrease $(p>0.05)$. The pressure difference across the coarctation of the aorta decreased markedly $(p<0.001)$. Closed circles represent infants $<18$ months old and open circles are data from children. There was no significant difference in the presssure response between infants and children after balloon angioplasty.

with severe valvar aortic stenosis underwent successful dilatation of the aortic valve at the same time.

Table 2 and fig 2 show the pressure measurements across the coarctation of the aorta and the diameter of the coarcted segment as measured by aortography before and immediately after dilatation. After balloon dilatation the systolic pressure proximal to the coarctation of the aorta $(129.5(29.3)) \mathrm{mm} \mathrm{Hg}$ decreased (116.3 (19.9)) but not significantly $(p>0.05)$, while systolic pressure distal to the coarctation of the aorta increased significantly $(p<0.02)$ from $86.4(17.7) \mathrm{mm} \mathrm{Hg}$ to $107.8(20.0)$. The systolic pressure gradient across the coarctation of the aorta decreased from 44.1 (19.1) to $8.5(8.5)$ $(p<0.001)$ after dilatation. Dilatation increased the diameter of the coarcted segment from $3.8(1.7) \mathrm{mm}$ to $8.5(3.1) \mathrm{mm}(\mathrm{p}<0.001)$ (table 2). Figure 3 shows examples of angiograms showing the increase in size of the coarcted segment after balloon dilatation.

There were no significant complications during or after the procedure. Two children required blood transfusions after considerable losses during catheter/guide wire exchanges. One child complained of tightness in the chest during balloon dilatation but no other symptoms were noted subsequently. After dilatation systolic hypertension, which lasted for over 12 hours, developed in one child who has otherwise remained symptom free; this resembled post-coarctectomy syndrome but was short lived.

The femoral pulses, which were either absent or considerably reduced and delayed (when compared with the brachial pulses) before balloon dilatation, became palpable with increased pulse volume after dilatation. Blood pressure measurements in the arms and legs on the morning after dilatation generally resembled pressure recordings obtained $15 \mathrm{~min}$ after dilatation. Suprasternal notch cross sectional echocardiography and Doppler flow studies with sample volume placed just distal to the level of coarction were performed before and on the morning after dilatation in six patients. The Doppler flow velocity decreased $(p<0.01)$ from $3.4(0.7) \mathrm{m} / \mathrm{s}$ to $1.9(0.5) \mathrm{m} / \mathrm{s}$, indicating a fall in calculated pressure difference from $47.8 \quad(20.9) \mathrm{mm} \mathrm{Hg}$ to 16.0 $(7.2) \mathrm{mm} \mathrm{Hg}(p<0.02)$. The four infants who were in heart failure improved after balloon dilatation. All patients were discharged home within 24 to 48 hours 

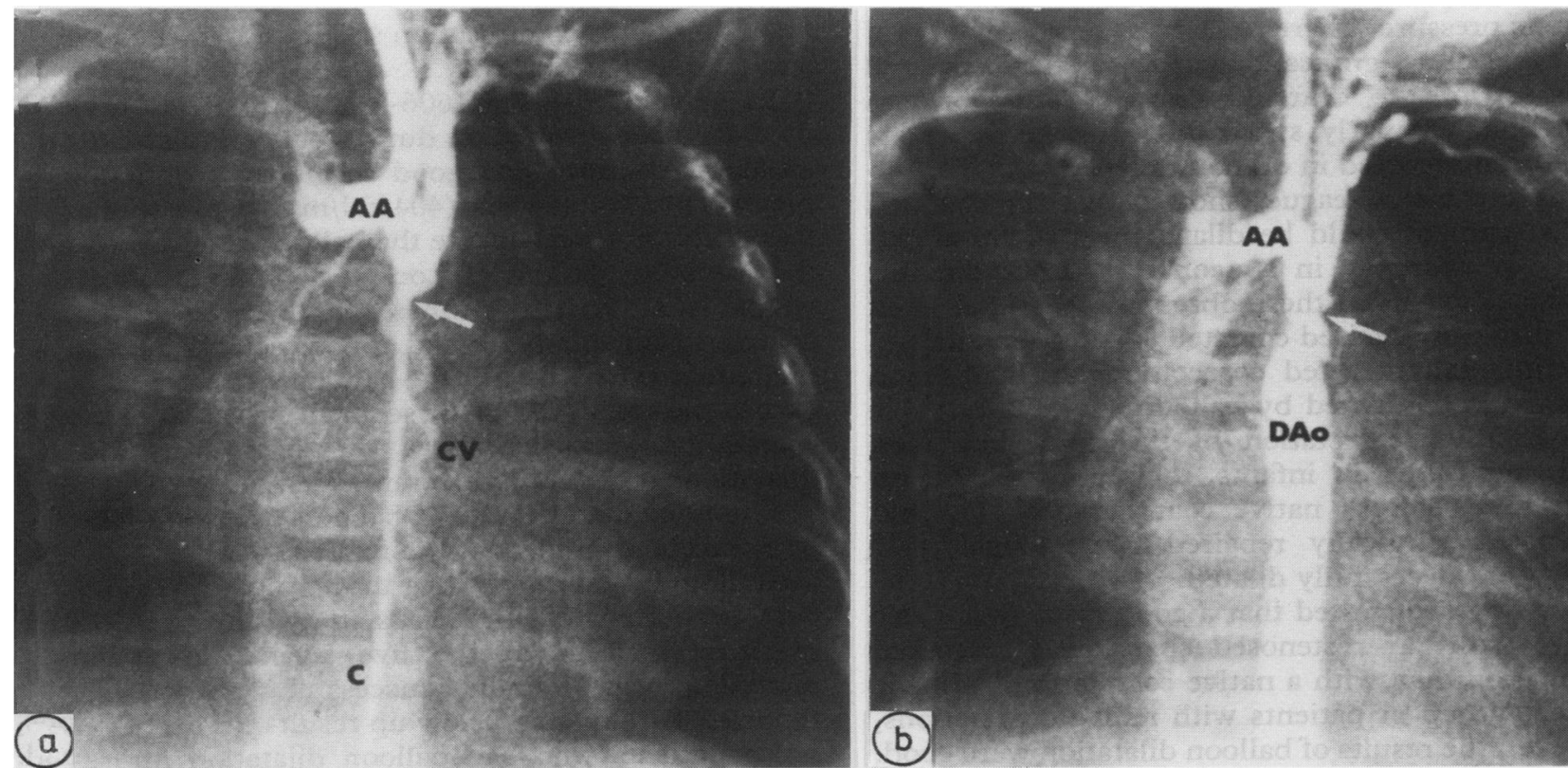

Fig 3 Aortic arch $(A A)$ angiography in posteroanterior projection before and after balloon angioplasty in an infant weighing $3.6 \mathrm{~kg}$. Before balloon angioplasty (a) there was no opacification of the descending aorta (DAo); this is presumably because there was almost complete obstruction of the coarcted segment by the catheter $(C)$. A collateral vessel (CV) was seen. Note clear cut opacification of DAo after balloon angioplasty $(b)$. The site of coarctation is marked with an arrow. Note the uneven opacification in the region of dilated coarctation; this probably represents intimal tears.

after dilatation. No long term follow up information is available in these patients. None of them, however, required immediate operation. Six children had been followed for three to seven months. The results of a repeat balloon dilatation, required three months after the first dilatation in one patient, were good. Five children showed good femoral pulses with systolic pressure differences of $0-15 \mathrm{~mm} \mathrm{Hg}$ between the arms and legs. In three babies suprasternal cross sectional echocardiography showed no significant narrowing and Doppler studies with the sample volume placed in the descending aorta showed flow velocities of 1.5 to $1.73 \mathrm{~m} / \mathrm{s}$, indicating a gradient $<12 \mathrm{~mm} \mathrm{Hg}$. Repeat cardiac catheterisation is planned for these children approximately one year after dilatation.

\section{Discussion}

PULMONARY VALVE STENOSIS

The right ventricular pressure and transpulmonary valvar gradient decreased in each patient after balloon dilatation whereas the cardiac index remained unchanged. These short term successful results resemble those reported by others. ${ }^{524}$ In some patients in this study (table 1) an infundibular gradient persisted after dilatation. In one patient with- out an infundibular pressure gradient but with angiographic infundibular narrowing, an infundibular gradient appeared for the first time after dilatation (case 12, table 1). This infundibular obstruction is likely to regress, as has been observed after surgical pulmonary valvotomy. ${ }^{25} 26$ Regression of an infundibular obstruction was reported in an adult patient after balloon pulmonary valvuloplasty $^{27}$ and in one of my patients in whom there was follow up data.

Although the long term benefits of balloon dilatation are not extensively documented several groups have reported good results. Kan and colleagues performed cardiac catheterisation 2-12 months after dilatation in nine patients and found persistent relief of right ventricular outflow obstruction. ${ }^{6}$ Miller reported the persistence of good results of balloon dilatation in six of seven patients followed up for 3-6 months. ${ }^{8}$ In the current series catheterisation results at follow up in ten patients 6-15 months after balloon dilatation showed that the improvement produced by dilatation was either maintained or improved (further decrease in right ventricular pressure and pulmonary valve gradient).

COARCTATION OF THE AORTA

In all patients there was a significant decrease in the 
systolic pressure difference across the coarctation of the aorta and significant increase in the measured diameter of the coarcted segment after balloon dilatation. Similarly successful short term results have been reported in other studies. ${ }^{14} 1517$

Sos and his colleagues showed that the coarcted aortic segment could be dilated by balloon angioplasty at necropsy in a neonate. ${ }^{28}$ Lock and his associates extended these observations and showed that surgically excised coarcted aortic segments and experimentally created coarctations in lambs and dogs could be dilated by balloon angioplasty. ${ }^{29-31}$ Dilatation of coarctation of the aorta has been used clinically in infants, children, ${ }^{141718}$ and adults. ${ }^{173233}$ Both native coarctations ${ }^{141617}$ and restenosed surgically repaired coarctations ${ }^{14} 1819$ have been successfully dilated.

Lock et al suggested that a good result was more likely with a restenosed previously repaired coarctation than with a native coarctation. ${ }^{14}$ In the present group of patients with native coarctations, however, the results of balloon dilatation were good. Lock also suggested that an increase of $\geqslant 30 \%$ in the diameter of the dilated segment and a fall of $\geqslant 50 \%$ in the gradient across coarctation 24 hours after dilatation are likely to indicate good clinical response. All the patients in the present study fulfilled these criteria and hence their long term results may be good.

Balloon dilatation relieves coarctation by tearing the intima and media. ${ }^{28-30}$ It is, therefore, most important not to manipulate catheters and guide wires in the area of a freshly dilated coarctation. Indeed, inadvertent manipulation has caused aortic perforation and death. ${ }^{16}$ A guide wire should be left in place in the ascending aorta for exchange of the balloon dilatation catheter with an angiographic catheter for post-dilatation angiography and pressure measurements. If the guide wire is inadvertently removed other methods such as main pulmonary artery cineangiography with levophase and indirect pressure measurements should be used to obtain data after dilatation. A syndrome of hypertension, abdominal pain, and bowel necrosis may develop after surgical repair of coarctation of the aorta (post-coarctectomy syndrome). This syndrome is rare, perhaps because awareness of the condition, together with monitoring and prompt treatment of hypertension after coarctation repair prevents full blown cases of post-coarctectomy syndrome from developing. One of the patients in the current study and an adult patient reported by Lababidi et $^{3 l^{33}}$ developed a forme fruste of this syndrome which resolved spontaneously. This indicates that a syndrome resembling the one that occurs after coarctectomy may also develop after balloon dilatation. This complication should be watched for and treated appropriately.

In general, $6-8 \mathrm{~atm}\left(606-808 \mathrm{kN} / \mathrm{m}^{2}\right)$ has been used for balloon inflation during balloon dilatation, although we have had good results with inflation pressures as low as $4 \mathrm{~atm}\left(404 \mathrm{kN} / \mathrm{m}^{2}\right)$. A pressure of $9\left(909 \mathrm{kN} / \mathrm{m}^{2}\right)$ can rupture the balloon. I agree with the recommendations of Lock et $\mathrm{al}^{14}$ that a balloon which is at least 2.5 times the diameter of the coarcted segment is needed for successful balloon dilatation. It may be that the balloon size should not exceed the size of the aortic segment proximal to the coarctation of the aorta. A total of at least four dilatations is generally recommended.

The immediate results of balloon dilatation have been excellent in most of the reported series, ${ }^{141719}$ including this one. Few long term follow up results have been reported. In Lock's study, improvement persisted in four of the five infants in whom dilatation was initially successful. ${ }^{14}$ Kan et al reported 1-14 month follow up results for six of the seven patients who had balloon dilatation for restenosed repaired coarctation. In all of them there was a sustained improvement of the systolic pressure gradient across the dilated coarctation of the aorta. ${ }^{19}$ Lababidi et al followed 13 of 27 patients for 3-24 months after balloon dilatation and found a good clinical improvement in all, no aneurysms, and an increased gradient across the coarctation in four of 13 patients. ${ }^{17}$ In the current study group, clinical follow up for 3-7 months showed good results in five of the six patients and the sixth patient underwent successful repeat dilatation. Although most studies did not show complications on long term follow up, some recent reports showed aneurysmal dilatation in the region of previously dilated coarcted aortic segment one year after dilatation. ${ }^{34}$ Such features are not unexpected in view of the thinning and interruption (tears) of the media seen after successful balloon dilatation of experimentally created or excised aortic coarctations. ${ }^{28-30}$

\section{Conclusion}

The risks of surgical pulmonary valvotomy have been considerably reduced. But open heart pulmonary valvotomy still has many disadvantages including prolonged hospital admission, scars, and greater cost. For these reasons alone relief of pulmonary valve stenosis by catheter techniques, even if the risk is comparable to that of surgical correction, would be attractive. Successful immediate results with excellent relief of pulmonary valve stenosis and indications that relief persists suggest that percutaneous balloon dilatation is the treatment of choice for moderate to severe pulmonary valve 
stenosis. When pulmonary valve stenosis is caused by dysplastic leaflets, however, balloon dilatation is not likely to be successful.

Although the long term results of balloon dilatation for coarctation of the aorta are not yet established the short term results are encouraging. In the light of the high risk of surgical resection of coarctation of the aorta in neonates and small infants especially when other intracardiac anomalies are present $^{35}$; a high incidence of recurrence $(10-30 \%)$ of coarctation in infants ${ }^{36-38}$; and the difficulties encountered during reoperation for recurrent coarctation ${ }^{3940}$ balloon dilatation of coarctation of the aorta offers a safer and effective alternative to surgical repair in infants. With balloon dilatation, surgery may be avoided or at least postponed until the child is larger and the risks of death and recoarctation are less. ${ }^{41}$ Recurrence of stenosis or the development of aneurysm at the site of dilatation can be treated by surgical resection when the acute illness has passed.

Published reports indicate that balloon dilatation for restenosed repaired coarctations is consistently effective without many complications. In older children (beyond infancy) with native coarctations, however, balloon dilatation should not be performed routinely until the risk of aneurysm has been assessed in long term studies.

I thank Dr M E Fawzy and Dr M K Mardini for their contribution to this study.

\section{References}

1 Rubio V, Limon-Lason R. Treatment of pulmonary valvular stenosis and of tricuspid stenosis using a modified catheter. Second World Congress of Cardiology, Washington, DC, 1954, Program abstracts II, p.205.

2 Dotter CT, Judkins MP. Transluminal treatment of arteriosclerotic obstruction: description of a new technic and a preliminary report of its application. Circulation 1964;30:654-70.

3 Zeitler E, Grüntzig A, Schoop W. Percutaneous vascular recanalization: technique, application, clinical results. Berlin: Springer-Verlag, 1978.

4 Grüntzig AR, Senning A, Siegethaler WE. Nonoperative dilatation of coronary artery stenosis: percutaneous transluminal coronary angioplasty. $N$ Engl f Med 1979;301:61-8.

5 Lababidi Z, Wu JR. Percutaneous balloon pulmonary valvuloplasty. Am f Cardiol 1983;52:560-2.

6 Kan JS, White RI Jr, Mitchell SE, et al. Percutaneous transluminal balloon valvuloplasty for pulmonary valve stenosis. Circulation 1984;69:554-60.

7 Rao PS, Mardini MK. Pulmonary valvotomy without thoracotomy: the experience with percutaneous balloon pulmonary valvuloplasty. Ann Saudi Med
1985;5:149-54.

8 Miller GAH. Balloon valvuloplasty and angioplasty in congenital heart disease. Br Heart $\mathcal{f}$ 1985;54:285-9.

9 Lock JE, Castaneda-Zuniga WR, Fuhrman BP, et al. Balloon dilatation angioplasty of hypoplastic and stenotic pulmonary arteries. Circulation 1983;67:962-7.

10 Massumi A, Woods L, Mullins CE, et al. Pulmonary venous dilatation in pulmonary veno-occlusive disease. Am f Cardiol 1981;48:585-9.

11 Driscoll DJ, Hesslein PS, Mullins CE. Congenital stenosis of individual pulmonary veins: clinical spectrum and unsuccessful treatment by transvenous balloon dilatation. Am f Cardiol 1982;49:1767-72.

12 Lock JE, Fuhrman BP, Castaneda-Zuniga WR, et al. Dilatation angioplasty (DA) of congenital cardiac defects: preliminary results [Abstract]. Circulation 1982;66(suppl II):360.

13 Lababidi Z, Wu J, Walls JT. Percutaneous balloon aortic valvuloplasty: results in 23 patients. $\mathrm{Am} \mathcal{F}$ Cardiol 1984;53:194-7.

14 Lock JE, Bass JL, Amplatz K, et al. Balloon dilatation angioplasty of aortic coarctation in infants and children. Circulation 1983;68:109-16.

15 Sperling DR, Dorsey TJ, Rowen M, et al. Percutaneous transluminal angioplasty of congenital coarctation of the aorta. Am $\mathcal{F}$ Cardiol 1983;51:562-4.

16 Finley JP, Beaulieu RG, Nanton MA, Roy DL. Balloon catheter dilatation of coarctation of the aorta in young infants. Br Heart $\mathcal{F}$ 1983;50:411-5.

17 Lababidi ZA, Daskalopoulos DA, Stoeckle H Jr. Transluminal balloon coarctation angioplasty: experience with 27 patients. $A m \quad \mathcal{F}$ Cardiol 1984;54:1288-91.

18 Singer MI, Rowen M, Dorsey TJ. Transluminal aortic balloon angioplasty for coarctation of the aorta in the newborn. Am Heart $\mathcal{F}$ 1982;103:131-2.

19 Kan JS, White RI Jr, Mitchell SE, et al. Treatment of restenosis of coarctation by percutaneous transluminal angioplasty. Circulation 1983;68:1087-94.

20 Waldman JD, Waldman J, Jones MC. Failure of balloon dilatation in mid-cavity obstruction of the systemic venous atrium after the Mustard operation. Pediat Cardiol 1983;4:151-4.

21 Benson LN, Yeatman L, Laks H. Balloon dilatation for superior vena caval obstruction after the Senning procedure: Cathet Cardiovasc Diagn 1985;11:63-8.

22 Rocchini AP, Cho KJ, Byrum C, et al. Transluminal angioplasty of superior vena cava obstruction in a 15-month old child. Chest 1981;82:506-8.

23 Requarth JA, Goldberg SJ, Vasko SD, et al. In vitro verification of Doppler prediction of transvalve pressure gradient and orifice area in stenosis. $\mathrm{Am} \mathcal{F} \mathrm{Car}$ diol 1984;53:1369-73.

24 Rocchini AP, Kveselis DA, Crowley D, et al. Percutaneous balloon valvuloplasty for treatment of congenital pulmonary valvular stenosis in children. $f \mathrm{Am}$ Coll Cardiol 1984;3:1005-12.

25 Engle MA, Holswade GR, Goldberg HP, et al. Regression after open pulmonary valvotomy of infundibular stenosis accompanying severe valvular pulmonic stenosis. Circulation 1958;17:862-73.

26 Griffith BP, Hardesty RL, Siewers RD, et al. Pul- 
monary valvulotomy alone for pulmonary stenosis: results in children with and without muscular infundibular hypertrophy. $\mathcal{F}$ Thorac Cardiovasc Surg 1982;83:577-83.

27 Pepine CJ, Gessner IH, Feldman RL. Percutaneous balloon valvuloplasty for pulmonic valve stenosis in the adult. $A m \mathcal{F}$ Cardiol 1983;50:1442-5.

28 Sos TA, Sniderman KW, Rettek-Sos B, et al. Percutaneous transluminal dilatation of coarctation of thoracic aorta-postmortem. Lancet 1979;ii:970-1.

29 Lock JE, Niemi T, Burke BA, et al. Transcutaneous angioplasty of experimental aortic coarctation. Circulation 1982;66:1280-6.

30 Lock JE, Castaneda-Zuniga WR, Bass JL, et al. Balloon dilatation of excised aortic coarctations. Radiology 1982;143:689-91.

31 Castaneda-Zuniga WR, Lock JE, Vlodaver Z, et al. Transluminal dilatation of coarctation of the abdominal aorta: experimental study in dogs. Radiology 1982;143:693-7.

32 Tegtmeyer CJ, Wellons HA, Thompson RN. Balloon dilatation of the abdominal aorta. $\mathcal{F} A M A$ 1980;244:2636-7.

33 Lababidi Z, Madigan N, Wu R, Murphy TJ. Balloon coarctation angioplasty in an adult. $\mathrm{Am} \mathcal{F}$ Cardiol 1984;53:350-1.

34 Cooper R, Ritter S, Golinko R. Balloon coarctation angioplasty: long term hemodynamic and angiographic results [Abstract]. Am Heart $\mathcal{F}$ 1985;110:706.

35 Hesslein PS, McNamara DG, Morriss MJH, et al. Comparison of resection versus patch aortoplasty for repair of coarctation in infants and children. Circulation 1981;64:164-8.

36 Waldhausen JA, Whitman V, Werner JC, Pierce WS. Surgical intervention in infants with coarctation of the aorta. I Thorac Cardiovasc Surg 1981;81:323-5.

37 Kamau P, Miles V, Toews W, et al. Surgical repair of coarctation of the aorta in infants less than six months of age including the question of pulmonary artery banding. I Thorac Cardiovasc Surg 1981;81:171-9.

38 Metzdorff MT, Cobanoglu A, Grunkemeier GL, Sunderland $\mathrm{CO}$, Starr A. Influence of age at operation on late results with subclavian flap aortoplasty. $\mathcal{f}$ Thorac Cardiovasc Surg 1985;89:235-41.

39 Brewer LA III, Fosburg RG, Mulder GA, et al. Spinal cord complications following surgery for coarctation of the aorta: a study of 66 cases. $\mathcal{F}$ Thorac Cardiovasc Surg 1972;64:368-81.

40 Cerilli J, Lauridsen P. Reoperation for coarctation of the aorta. Acta Chir Scand 1965;129:391-4.

41 Lerberg DB, Hardesty RL, Siewers RD, et al. Coarctation of the aorta in infants and children: twenty five years of experience. Ann Thorac Surg 1982;33:159-70. 